\title{
Response of tidal flow regime and sediment transport in North Malé Atoll, Maldives, to coastal modification and sea level rise
}

\author{
Shuaib Rasheed ${ }^{1}$, Simon C. Warder ${ }^{1}$, Yves Plancherel ${ }^{1,2}$, and Matthew D. Piggott ${ }^{1}$ \\ ${ }^{1}$ Department of Earth Science and Engineering, Imperial College London, London, UK \\ ${ }^{2}$ Grantham Institute - Climate Change and the Environment, Imperial College London, London, UK
}

Correspondence: Shuaib Rasheed (s.rasheed18@imperial.ic.ac.uk)

Received: 12 August 2020 - Discussion started: 7 September 2020

Revised: 17 December 2020 - Accepted: 4 January 2021 - Published: 17 February 2021

\begin{abstract}
Changes to coastlines and bathymetry alter tidal dynamics and associated sediment transport processes, impacting upon a number of threats facing coastal regions, including flood risk and erosion. Especially vulnerable are coral atolls such as those that make up the Maldives archipelago, which has undergone significant land reclamation in recent years and decades and is also particularly exposed to sea level rise. Here we develop a tidal model of Male Atoll, Maldives, the first atoll-scale and multi-atollscale high-resolution numerical model of the atolls of the Maldives and use it to assess potential changes to sediment grain size distributions in the deeper atoll basin, under sea level rise and coastline alteration scenarios. The results indicate that the impact of coastline modification over the last two decades at the island scale is not limited to the immediate vicinity of the modified island but can also significantly impact the sediment grain size distribution across the wider atoll basin. Additionally, the degree of change in sediment distribution which can be associated with sea level rise that is projected to occur over relatively long time periods is predicted to occur over far shorter time periods with coastline changes, highlighting the need to better understand, predict and mitigate the impact of land reclamation and other coastal modifications before conducting such activities.
\end{abstract}

\section{Introduction}

Driven by their importance to the coastal zone, the response of tidal dynamics and sediment to future sea level rise (SLR) scenarios as well as to coastal modification has been considered in various studies targeting different locations around the world, ranging from marginal seas such as the Bohai Sea (e.g. Pelling et al., 2013), shelf seas such as the northwestern European continental shelf (e.g. Ward et al., 2012), and estuaries and bays such as the Eastern Scheldt estuary (e.g. Jiang et al., 2020). However, the response of sediment distribution in large coral atolls to anthropogenic pressures such as land reclamation and coastal modification remains poorly studied and is generally restricted to very small patch reefs for a variety of reasons including remoteness and lack of data. Recent availability of a high-resolution bathymetry dataset for the Maldives archipelago (Rasheed et al., 2021) now allows for the application of numerical models capable of studying the hydrodynamics within the large coral atolls of the archipelago at high fidelity for the first time.

The relationship between tidal currents and sediment distribution patterns has been considered as early as Kenyon (1970) through field observations. Pingree and Griffiths (1979) used a numerical model to derive a correlation between sand transportation pathways and bed shear stress derived from the combined M2 and M4 tidal constituents in the shelf seas around the UK. Warwick and Uncles (1980) used tidal bed shear stress derived from a numerical model to infer benthic sediment in the Bristol Channel and identified the issue of overlapping bed shear stress values derived from numerical models and multiple bed sediment types. Ward et al. (2015) further developed a classification scheme for bed shear stress derived from a numerical model and correlated it with the observed dominant seabed sediment type, resolving the issue of overlapping bed sediment types and modelled bed shear stress values.

Studies (e.g. Haigh et al., 2020; Holleman and Stacey, 2014; Jiang et al., 2020) have shown that the response of the 
tides to changing physical characteristics such as bathymetry and coastline modification can vary significantly in different areas depending on the local geological setting. According to these studies the response in some environments is more complex than others due to the effects of processes such as shoaling, damping and resonance. Holleman and Stacey (2014) reported significant tidal amplification increases resulting from sea level rise in San Pablo bay, California, due to the complex bathymetry of the region. Similarly, coral atolls, described as being analogous to large "leaky buckets" (Gischler, 2006) composed of drowned carbonate platforms with extremely complex topographic features such as steep vertically rising lagoons, channels and oceanic faros (a Maldivian term for ring-shaped reefs found in the centre or on the rim of larger composite atolls; Agassiz, 1902), will be subject to similarly complex responses. This is supported by field data from different sources including Betzler et al. (2015), Gischler (2006) and Morgan and Kench (2014), who studied the bed sediment in different areas of the Maldives archipelago at different scales ranging from regional (e.g. atoll) scales to localised (e.g. individual island or lagoon) scales.

The aim of this study is to construct a classified bed sediment map of North Malé atoll, Maldives, using tidal simulations validated against available tidal and sediment field measurements, and to use this tool to quantify the response to sea level rise and large-scale land reclamation scenarios. The strong correlation reported between velocity patterns and dominant bed sediment grain size in coral atolls provides grounds and data to derive an estimated grain size distribution from the outputs of tidal simulations, which can be further used to classify the bed shear stress at the atoll level and also to understand the potential response of atoll systems to anthropogenic pressures. Identification of potential bed sediment type is important for a variety of reasons ranging from the identification of potential dredging sites, the determination of water turbidity, and the identification of potential habitats for benthic flora and fauna. The methods described in this study can be applied to other coral atolls of the Maldives and other regions elsewhere with similar geological settings and where there are limitations in accessing field data.

\section{Study site}

\subsection{General setting}

The Maldives archipelago, shown in Fig. 1a, is located to the south-west of the Indian subcontinent. Bounded by the $2000 \mathrm{~m}$ bathymetric contour of the Chagos-Laccadive ridge, the archipelago ranges over approximately $1000 \mathrm{~km}$ from north to south and $150 \mathrm{~km}$ from east to west. The 22 atolls that form the Maldives archipelago each have their own unique characteristics and range in size from a few kilometres to tens of kilometres (Wells, 1988), encompassing thou-

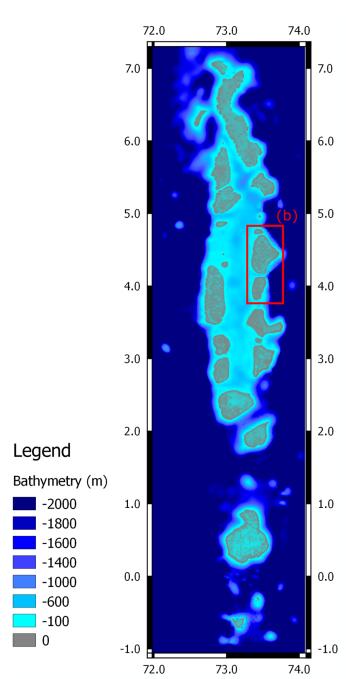

(a)

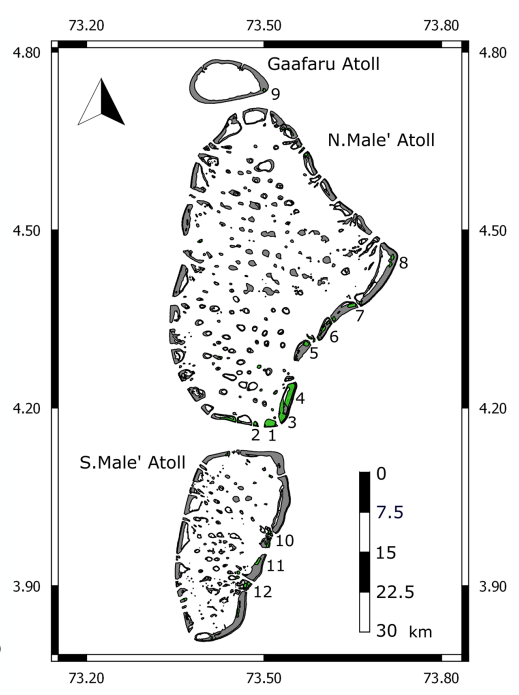

(b)
Figure 1. (a) Bathymetry of the Maldives archipelago as per Rasheed et al. (2021). (b) The study region which includes the atolls of Gaafaru atoll, North Malé atoll and South Malé atoll with the shallow water lagoons (grey) and islands (green) marked. Inhabited islands, excluding industrial islands, are labelled as (1) Malé, (2) Villingilli, (3) Hulhulé, (4) Hulhumalé, (5) Himmafushi, (6) Huraa, (7) Thulusdhoo, (8) Dhiffushi, (9) Gaafaru, (10) Gulhi, (11) Maafushi, (12) Guraidhoo; boundaries of lagoons based upon Spalding et al. (2001).

sands of individual reefs and more than 1200 low-lying islands (Naseer and Hatcher, 2004). None of the islands exceed more than a few metres in height above current sea level. The most prominent feature of the Maldives archipelago is the arrangement of the double chain of atolls in the central zone of the archipelago separated by the Maldives inner sea with depths typically in the range 300-500 m (Purdy and Bertram, 1993). Even though there have been a limited number of studies, the geological features of Maldives coral atolls and their formation have been discussed since observations obtained from field expeditions in the late 19th and early 20th centuries (e.g. Gardiner, 1902, 1903; Glennie, 1936; Hass, $1965)$ as well as more recent studies in the past few decades (e.g. Aubert and Droxler, 1992, 1996; Purdy and Bertram, 1993; Belopolsky and Droxler, 2003, 2004).

Located in the doldrums, the Maldives does not generally experience major storms, and the climate is primarily influenced by the seasonal fluctuations of the South Asian monsoonal wind patterns, with the wind speed averaging $5 \mathrm{~m} \mathrm{~s}^{-1}$ for both the north-eastern and south-western monsoons. The archipelago experiences a semidiurnal microtidal regime with a tidal range of approximately $1 \mathrm{~m}$ (Caldwell et al., 2015). The combined tidal- and wind-driven currents can exceed speeds of $2 \mathrm{~m} \mathrm{~s}^{-1}$, particularly in the channels separating the atolls, along the ocean-facing flanks of atoll rims and through gaps in atoll rims (Ciarapica and Passeri, 
1993). The absence of major storms and relatively low wind speeds across the archipelago suggest that the currents across the archipelago, particularly in areas of deeper water, are mainly driven by tides.

The impact of wind-driven sediment transport has been discussed in several studies, as presented in Sect. 2.3.1, particularly with respect to attempts to understand the formation of the Maldives, and the presence of faros in the atolls of the Maldives being attributed to the influence of changes in monsoonal wind patterns(Purdy and Bertram, 1993; Naseer and Hatcher, 2000). However, studies such as that of Gischler (2006), which attempted to statistically correlate the presence of geomorphological features in the atolls of the Maldives with various different geological parameters, found that wind speeds do not have a significant statistical correlation with the abundance of faros and lagoon reefs within the larger atoll basin. Further, the correlation between both the number of lagoonal faros and marginal faro areas with the wind stress were found to be statistically insignificant. Additionally, studies also show that the island shape influences the morphological change of the islands more than wave exposure (Kench et al., 2009). This provides more support to the argument that while winds dominate sediment transport processes in shallow areas of the atoll (which overall constitute a small area of the wider, deeper atoll basin, as illustrated in grey in Fig. 1b) the influence of wind decreases in deeper areas, with the tides being the major driver for sediment transport processes at these depths.

\subsection{Malé Atoll}

Malé atoll is an administrative unit in the Maldives archipelago located on the north-eastern side of the double chain of atolls of the Maldives archipelago and is comprised of the geographic atolls of Kaashidhoo, Gaafaru, and North and South Malé atolls. Kaashidhoo atoll, classified as an oceanic platform reef, is separated from the other parts of the administrative unit by deep channels exceeding $500 \mathrm{~m}$ separating the atoll on all sides. Due to the distance from the main geographical areas of the administrative atoll and its distinct nature, Kaashidhoo atoll was not included in this study.

Gaafaru atoll, seen in Fig. 1b, also classified as an oceanic faro (Naseer and Hatcher, 2004), is a small atoll $15 \mathrm{~km}$ in width and $8 \mathrm{~km}$ in length with a surface area of $88.50 \mathrm{~km}^{2}$. The atoll, similar to other atolls classified as oceanic faros across the country, is significantly smaller than the larger more complex atolls. The outer rim of Gaafaru atoll has no major openings besides two channels in the north of the atoll. The only island in the atoll is Gaafaru island to the southeast, and no other lagoon or faro exists in the atoll. The atoll is separated from North Malé atoll by the narrow, deep channel Hani Kandu which is $3 \mathrm{~km}$ wide with depths of up to $160 \mathrm{~m}$ in the central region of the channel (Luthfee, 1995). We include Gaafaru atoll in the simulations conducted here because field studies (Gischler, 2006) suggest that smaller atolls of the archipelago have different characteristics compared to the larger more complex atolls in terms of their response to changes in tides and wind patterns.

North Malé atoll and South Malé atoll, seen in Fig. 1b, are both large complex atolls making up the bulk of the area of the administrative unit of Malé atoll. The larger North Malé atoll measures $60 \mathrm{~km}$ in length and $40 \mathrm{~km}$ in width with a surface area of $\sim 1623.92 \mathrm{~km}^{2}$. The atoll contains more than 189 individual reefs for a total reef area of $349 \mathrm{~km}^{2}$ (Naseer and Hatcher, 2004). The atoll has numerous faros, particularly concentrated in the southern and the northern regions of the atoll, with the faros found in the southern zone being more shallow and prominent. The atoll also consists of numerous islands, both natural and reclaimed. The southern islands of the atoll, which include the major islands of Malé (the capital island of the country), Hulhulé, Hulhumalé and Vilingilli, are home to more than 150000 people, which represents more than a third of the population of the entire country. To accommodate the socio-economic changes that have occurred over the past few decades, fuelled largely by the tourism industry, almost all islands in the atoll have experienced coastal modifications in terms of both harbour construction and land reclamation activities, with nearly half of all the currently existing land being reclaimed (Duvat and Magnan, 2019). This makes the location an ideal setting within which to consider the impact of such anthropogenic modifications.

South Malé atoll is separated from North Malé atoll by a $5 \mathrm{~km}$ wide channel Vaadhoo Kandu, with depths of close to $400 \mathrm{~m}$ in its central regions (Luthfee, 1995). South Malé atoll has a surface area of $\sim 558.31 \mathrm{~km}^{2}$. The atoll also has numerous reefs with 112 individual reefs identified (Naseer and Hatcher, 2004), with a combined area of $\sim 175.60 \mathrm{~km}^{2}$. However, unlike North Malé atoll where the outer rim is cut with numerous channels, the outer rim of South Malé atoll is more continuous with fewer channels separating the outer rim. While South Malé atoll has also seen extensive land reclamation, these activities at large scale have occurred only in the last few years, and the changes are thus not included in this study. However, sediment grain size data available for the atoll (Betzler et al., 2016) were used as the main source of observational data to derive the grain size tidal proxy.

\subsection{Sediment data}

The bed sediment of the coral atolls of the Maldives archipelago has been examined by several studies at the local scale across individual reefs, as well as at a regional scale spanning one or more atolls, mainly for the purposes of better understanding the formation of the archipelago (Ciarapica and Passeri, 1993). However, the correlation between bed sediment type and flow patterns in the Maldives archipelago has been known since Darwin (1842). With the sediment entirely devoid of terrigenous input due to the distance from major landmasses over the past 55 Myr (Belopolsky and 
Droxler, 2003; Aubert and Droxler, 1992), most bed sediment studies in the archipelago have focused on identifying the biological composition of the benthic surface, with a minimal number of studies focusing on sedimentary dynamics, especially at regional (atoll) scales (e.g. Betzler et al., 2015; Naseer, 2003).

\subsubsection{Localised (island/lagoon scale data)}

The sediment patterns around Funadhoo island in North Malé atoll, described by Kohn (1964), indicate a sediment pattern dominated heavily by wind waves. Located on the channel between Malé and Hulhulé, the island is exposed to continuous heavy swells, with thin layers of finer particles such as sand confined to areas of the lagoon that are less exposed. This observation of wind-driven sediment patterns in the shallow lagoons of the Maldives archipelago was further studied by Kench et al. (2009) and Kench and Brander (2006), who reported large movements of sand horizontally around islands due to changes in monsoonal wind patterns. Further, quantitative studies of sediment transport patterns in Vabbinfaru reef in North Malé atoll by Morgan and Kench (2014) between two monsoonal periods showed that significant quantities of sediment are transported from the lagoon to the atoll basin, with the main mode of transportation identified as wind-driven waves associated with the south-western monsoon. These studies suggest a wind-dominated sediment transport pattern for shallow lagoon areas of the Maldives archipelago. However, as discussed in the next section, observational data from the atoll basin which makes up more than $80 \%$ of the total area of the atolls, including marine benthic fauna and sediment data, indicate that beyond the shallow water areas tides dominate the sediment transport regime, which will be the focus of this study. More recently, East et al. (2020) used a hydrodynamic model to study the impact of waves and SLR across a small section of a reef in Huvadhoo atoll and suggested that morphological changes in sediment as well as island migration might occur under SLR scenarios.

\subsubsection{Regional (atoll-scale data)}

\section{North Malé Atoll and Felidhé Atoll}

The coral growth patterns in North Malé atoll and Felidhé atoll studied by Ciarapica and Passeri (1993) were observed to have hard bottoms in areas exposed to high currents, such as the oceanward rim of the atolls and channels, where the combined tidal and wind currents can be in excess of $2 \mathrm{~m} \mathrm{~s}^{-1}$ (Owen et al., 2011). Detailed studies of the micro atoll of Rasdhoo (e.g. Klostermann et al., 2014; Klostermann and Gischler, 2015; Gischler, 2006; Parker and Gischler, 2011) identified major bed sediment types with regards to foraminifera and facies that correlate well with current patterns. Areas exposed to major currents such as in channels in the outer rim as well as the flanks of the outer atoll were found to be of hard-bottom types, and areas with least exposure to strong currents were found to have the highest concentrations of mud and silt. The association of coral types and growth patterns with varying currents across the atoll indicate a tidally dominated transport pattern across the deep atoll basin (CDE Consulting, 2020a).

\section{South Malé Atoll}

The most extensive bed sediment study of an atoll within the Maldives archipelago was carried out by Betzler et al. (2015), who collected bed sediment data (Betzler et al., 2016) at different locations of South Malé atoll, Ari atoll and the Maldives inner sea. Importantly, the benthic foraminifera composition at these locations were further classified under five major grain size classes. Figure 2a, which illustrates the field data from Betzler et al. (2015), shows that the bed sediment of the major channels in both the east and west of South Malé atoll is dominated by hard-bottom types with a gradual increase in fine particles propagating towards the centre of the atoll. Locations sheltered from major ocean currents, such as the sheltered area in the north-east of South Malé atoll, are dominated by a mixture of mud, pelite (fine fragments of sedimentary rocks) and sand with a small presence of coarse granules. Other areas show a gradual mixture of particles influenced by the velocity patterns arising due to variations in bathymetry. Regions of the atoll basin in the periphery of high-flow regions such as around the drowned lagoons found in the central parts are dominated by medium sand deposited during peak flow and ebb.

\section{Methods}

\subsection{Tidal model}

In this study we use the Thetis coastal ocean model, a 2D (Angeloudis et al., 2018) and 3D (Kärnä et al., 2018; Pan et al., 2019) flow solver constructed using the Firedrake finite-element solver framework (Rathgeber et al., 2016). Here we use the 2D implementation of Thetis which solves the depth-averaged nonlinear shallow water equations in non-conservative form, given by

$$
\begin{aligned}
& \frac{\partial \eta}{\partial t}+\nabla \cdot\left(H_{\mathrm{d}} \boldsymbol{u}\right)=0, \\
& \frac{\partial \boldsymbol{u}}{\partial t}+\boldsymbol{u} \cdot \nabla \boldsymbol{u}-v \nabla^{2} \boldsymbol{u}+f \boldsymbol{u}^{\perp}+g \nabla \eta=-\frac{\tau_{\mathrm{b}}}{\rho H_{\mathrm{d}}},
\end{aligned}
$$

where $\eta$ is the free surface displacement (m), $H_{\mathrm{d}}$ is the total water depth (m), $\boldsymbol{u}$ is the depth-averaged velocity vector $\left(\mathrm{m} \mathrm{s}^{-1}\right)$ comprising $u$ and $v$ in the $x$ and $y$ directions respectively, and $v$ is the kinematic viscosity of the fluid $\left(\mathrm{m}^{2} \mathrm{~s}^{-1}\right)$. The term $f \boldsymbol{u}^{\perp}$ accounts for the Coriolis force, where $f=$ $2 \Omega \sin (\zeta)$, with $\Omega$ the angular rotation of the Earth, $\zeta$ the latitude and $\boldsymbol{u}^{\perp}$ the velocity vector rotated $90^{\circ}$. 


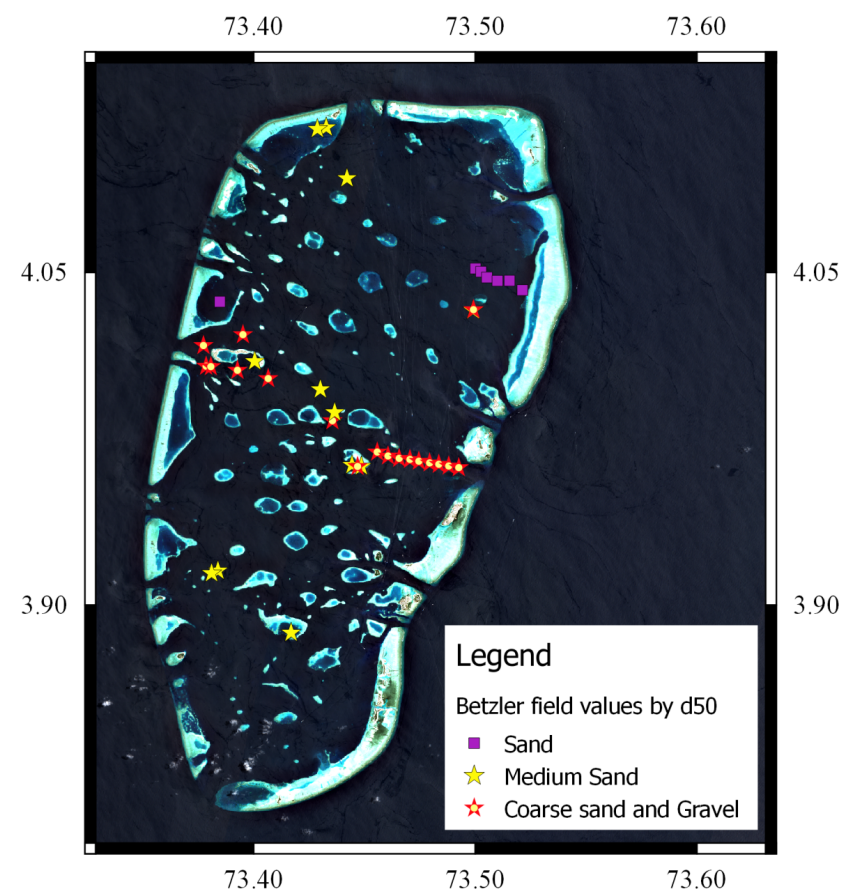

Figure 2. $d_{50}$ values for field data obtained by Betzler et al. (2016) laid over Sentinel-2 satellite imagery of South Malé atoll, binned according to grain size classification.

The model uses a discontinuous Galerkin-based finiteelement discretisation (DG-FEM), specifically the $P_{1}^{\mathrm{DG}}$ $P_{1}^{\text {DG }}$ finite-element pair where piecewise-linear discontinuous function spaces are used to represent both the velocity and the free surface prognostic fields. For time-stepping, a Crank-Nicolson approach is applied with a constant time step of $\Delta t=45 \mathrm{~s}$. The model treats wetting and drying according to the formulation of Kärnä et al. (2011), which introduces a modified bathymetry $\tilde{h}=h+f\left(H_{\mathrm{d}}\right)$ to always ensure a positive total water depth, with $f\left(H_{\mathrm{d}}\right)$ defined as

$f\left(H_{\mathrm{d}}\right)=\frac{1}{2}\left(\sqrt{H_{\mathrm{d}}^{2}+\alpha^{2}}-H_{\mathrm{d}}\right)$,

where $H$ is the water height, and $\alpha$ is a tunable constant. Bed shear stress $\tau_{\mathrm{b}}$ is implemented through the Manning's $n$ formulation

$\frac{\tau_{\mathrm{b}}}{\rho}=g n^{2} \frac{|\boldsymbol{u}| \boldsymbol{u}}{H_{\mathrm{d}}^{1 / 3}}$.

All simulations were carried out for the period of 00:00 1 January 2018 to 24:00 5 January 2018, which corresponded to a spring tide in the region. A further $2.5 \mathrm{~d}$ of simulation was included at the start to allow for the model dynamics to spin up from a state of rest. The wetting and drying constant $\alpha$ parameter (Kärnä et al., 2011) was set to $0.5 \mathrm{~m}$, and the tidal model was forced with 11 tidal constituents (M2, S2, $\mathrm{N} 2, \mathrm{~K} 2, \mathrm{O} 1, \mathrm{P} 1, \mathrm{Q} 1, \mathrm{M} 4, \mathrm{MS} 4$ and MN4) at the open bound- aries interpolated from the TPXO database (Egbert and Erofeeva, 2002). Harmonic analysis of long-term tide gauge data of the region have identified these constituents as having significant contributions to the combined tidal amplitude in the region (Rasheed et al., 2021).

\subsection{Model set-up}

\subsubsection{Bathymetry}

The complex bathymetry of the Maldives archipelago is not captured by any existing (global) bathymetry datasets; until recently, this has precluded regional-scale (atoll-scale) high-resolution modelling. However, recent developments (Rasheed et al., 2021) using satellite data, navigational charts and other sources have produced accurate bathymetry datasets at very high resolution for the first time, facilitating such studies as that presented here. Given the scale of the simulations carried out in this study, we use the highest available spatial resolution bathymetry dataset of $0.35 \mathrm{arcsec}$ $(\approx 10 \mathrm{~m})$. Figure 3 shows the bathymetry of North Malé atoll and Gaafaru atoll interpolated onto a mesh used for the simulations conducted here. The complex features of the atoll, including the narrow channels of the outer rim and the numerous lagoons within the atoll, are well captured.

\subsubsection{Coastline data}

Coastline data for two model set-ups, corresponding to the present-day and 1997 coastlines, were extracted from a variety of sources, since widely used global coastline datasets do not accurately capture all islands within the domain, and no coastline datasets exist for previous years. Coastline data for 2018 were chosen as the present-day coastline, and 1997 data were chosen as an "unmodified" coastline. Coastline data for 1997 were selected in this context because major reclamation works in the atoll in addition to Malé island, such as the reclamation of the lagoon of Hulhule to create the artificial island of Hulhumalé, began soon after.

Coastline data for the 2018 simulation were obtained from the GADM database (Areas, 2018). However, where this data did not represent the latest changes to the coastlines, Band8A (Narrow infrared) Sentinel-2 satellite images were used to extract the coastlines, particularly at Hulhumalé, Malé and several newly reclaimed islands at the north-west and northeast of the atoll, to provide a better representation of the coastline of North Malé atoll as of March 2018.

For simulations conducted based upon the 1997 coastline data, the coastlines were extracted from Landsat 5 satellite imagery. The single tile LT05_L1GS_145057_19970203_20170102_01_T2 was used, which provides a nearly cloudless image of the domain area, captured on 3 February 1997. While other sources provide coastline data across the Maldives archipelago to varying degrees of accuracy, we found extraction of 


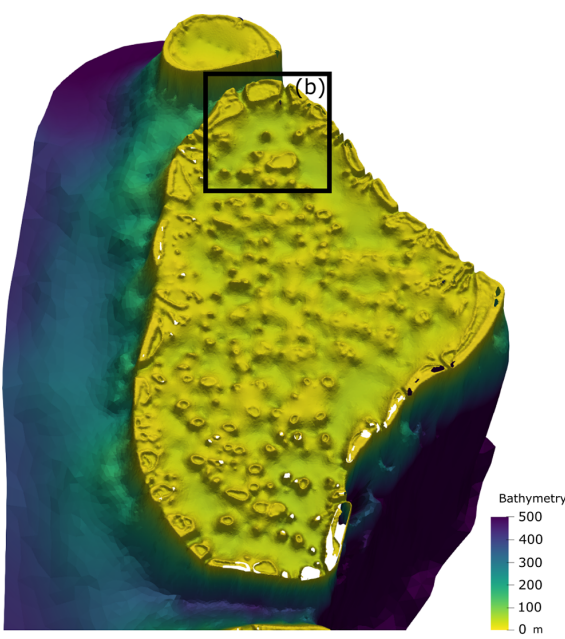

(a)

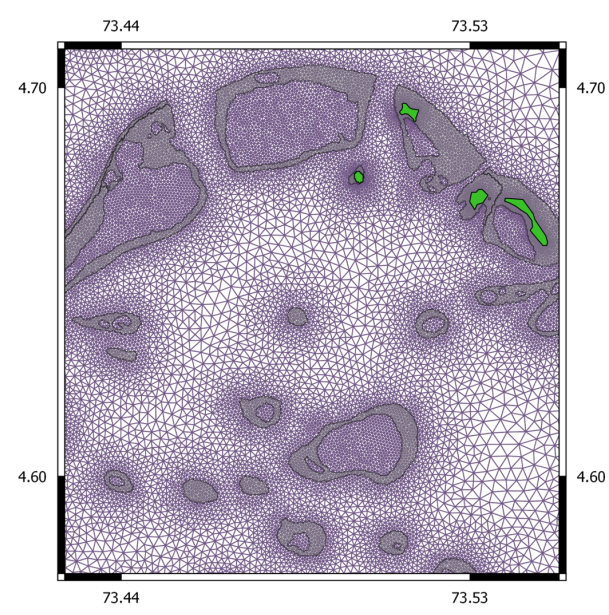

(b)

Figure 3. (a) Bathymetry of North Malé and Gaafaru atoll interpolated onto a simulation mesh. Bathymetry is exaggerated in the vertical for better visualisation and shows that the individual complex features of the atoll are well captured. (b) Part of the unstructured mesh used for the simulations conducted in this work, focused on northern North Malé atoll. Mesh resolution is increased significantly at lagoons and coastlines.

coastline contours from satellite imagery to be the best way to handle extremely complex and fragmented coastlines such as those in the Maldives. The tidal effect was not considered, mainly because the region experiences a micro tidal regime (Caldwell et al., 2015).

\subsubsection{Bed friction}

A uniform Manning drag coefficient was applied across the domain. According to various studies (e.g. Rosman and Hench, 2011), drag parameters across coral reefs are poorly understood and depend on many factors, requiring further study. Given sufficient observation data, it may be possible to perform a model calibration exercise for the uncertain coefficient (Warder et al., 2020), but this is not conducted here. Instead, the commonly applied value of $0.025 \mathrm{~s} \mathrm{~m}^{-1 / 3}$ was used. This results in a quadratic drag coefficient $\left(C_{\mathrm{D}}\right)$ varying from $\sim 0.0005$ in open-ocean regions up to $\sim 0.026$ for the shallow reefs and lagoons across the domain and is consistent with studies reporting the drag coefficient $\left(C_{\mathrm{D}}\right)$ within reef environments, composed of coral reefs and shallow lagoons (Kraines et al., 1998).

\subsubsection{Unstructured mesh generation}

The mesh for the model was set up using "qmesh", a Python package for constructing flexible unstructured meshes for geophysical models (Avdis et al., 2016, 2018) which utilises the "Gmsh" mesh generator (Geuzaine and Remacle, 2009). The use of unstructured meshes offers significant advantages in representing small spatial features across large geographical extents due to their flexibility over resolution and ge-
Table 1. Summary of the different meshes and scenarios simulated in the study.

\begin{tabular}{ccccl}
\hline Simulation & $\begin{array}{c}\text { No. of } \\
\text { nodes }\end{array}$ & $\begin{array}{c}\text { No. of } \\
\text { elements }\end{array}$ & Coastline & Sea level \\
\hline 1 & 190200 & 380574 & 2018 & MSL \\
2 & 184669 & 369486 & 1997 & MSL \\
3 & 190200 & 380574 & 2018 & MSL $+2.0 \mathrm{~m}$ \\
\hline
\end{tabular}

ometry (Piggott et al., 2008). The meshes that were used for this work were selected based on a sensitivity study which is described in Sect. 3.3 and Table 2. For all meshes, the element size at the coastlines was fixed at $50 \mathrm{~m}$, with slightly coarser refinement at reef and lagoon boundaries, and with elements allowed to gradually increase in size to the open boundary. Given the varying distances to this boundary, the element sizes there ranged from $500 \mathrm{~m}$ to more than $2000 \mathrm{~m}$. All meshes used for the simulations were generated in the UTM43N coordinate reference system.

Table 1 provides a summary of the meshes and simulation scenarios performed in the study, following the initial sensitivity study. The triangular element size ranged from $50 \mathrm{~m}$ at the island boundaries to up to $2300 \mathrm{~m}$ at the open boundary, with refinement to $100 \mathrm{~m}$ at the lagoon (reef) boundaries for all three scenarios. 
Table 2. Summary of the different meshes used for the study. The mesh resolution at the coastlines was set at $50 \mathrm{~m}$ and permitted to gradually increase in size up to $15 \mathrm{~km}$ towards the open boundaries.

\begin{tabular}{ccrr}
\hline $\begin{array}{c}\text { No. of } \\
\text { nodes }\end{array}$ & $\begin{array}{c}\text { No. of } \\
\text { elements }\end{array}$ & $\begin{array}{r}\text { Resolution at } \\
\text { lagoon }(\mathrm{m})\end{array}$ & $\begin{array}{r}\text { Distance to } \\
\text { boundary }(\mathrm{km})\end{array}$ \\
\hline \multicolumn{2}{l}{ Sensitivity to resolution at lagoon } \\
\hline 190200 & 380574 & 100 & 20 \\
82243 & 164660 & 300 & 20 \\
74138 & 148450 & 500 & 20 \\
72356 & 144886 & 700 & 20 \\
71788 & 143750 & 900 & 20 \\
\hline Sensitivity to distance to boundary & 20 \\
\hline 82243 & 164660 & 300 & 15 \\
81772 & 163718 & 300 & 10 \\
80983 & 162140 & 300 & 5 \\
79618 & 159410 & 300 & 2 \\
76074 & 152322 & 300 & \\
\hline
\end{tabular}

\subsection{Model sensitivity}

In order to select the most appropriate domain extent (i.e. distance to the open forcing boundary) and mesh resolution pattern in space, a sensitivity study for these choices was conducted through a series of numerical experiments, using the meshes in the configurations summarised in Table 2. The correlation of the simulation data to observations and between simulations was studied through the use of the correlation coefficient $R$ defined as

$$
R=\frac{\sum_{n=1}^{N}\left(O_{n}-\bar{O}\right)\left(M_{n}-\bar{M}\right)}{\sqrt{\sum_{n=1}^{N}\left(O_{n}-\bar{O}\right)^{2} \sum_{n=1}^{N}\left(M_{n}-\bar{M}\right)^{2}}},
$$

where $N$ is the number of data points, $O_{n}$ and $M_{n}$ are the observed and modelled values, and $\bar{O}$ and $\bar{M}$ are the means of the observed and modelled values respectively. As described below, we used the correlation coefficient to identify the appropriate resolution for the mesh in order to represent the bathymetry within the domain and also to investigate the sensitivity of the simulated tidal amplitude to mesh resolution and distance to the open (i.e. forcing) boundary.

The correlation coefficient is indicative of the linear least squares fit between the modelled and observed values and has been used widely for sensitivity studies of ocean models (O'Neill et al., 2012). The square of the coefficient, $R^{2}$, provides a measure of the variation between the observed and modelled values ranging from 0 for no correlation up to 1 for perfect correlation.

\subsubsection{Mesh resolution}

Since the bathymetry of the domain is highly complex and dominates the flow patterns in the region (Rasheed et al.,
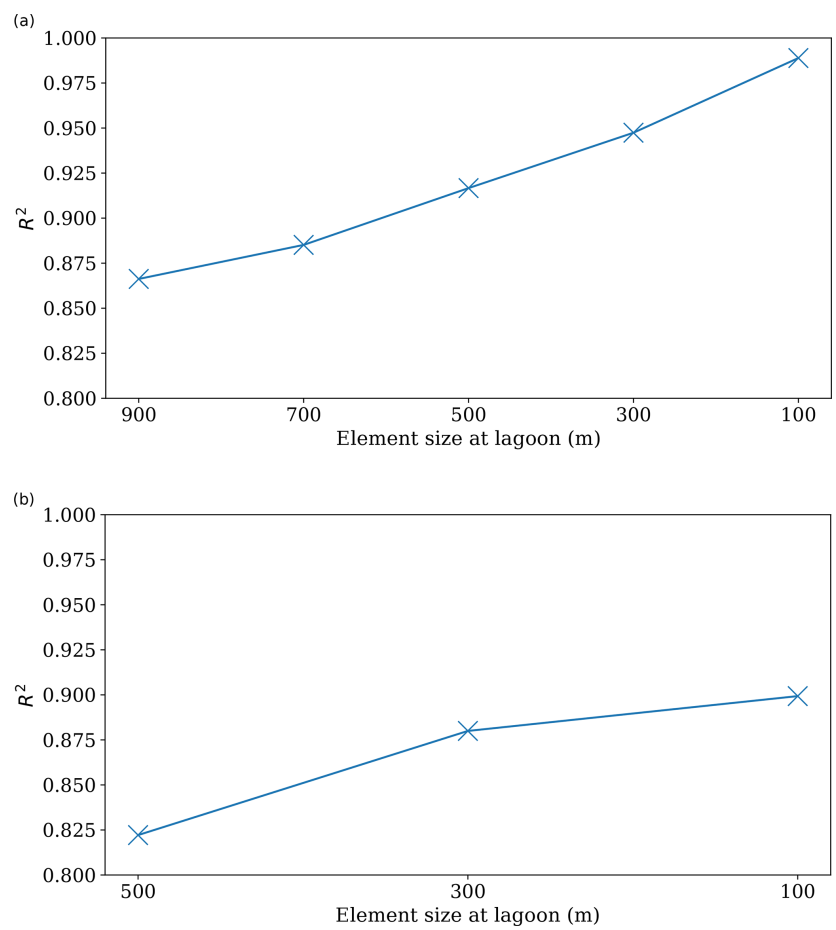

Figure 4. (a) Correlation between bathymetry interpolated onto mesh and the original high-resolution bathymetry dataset for different element sizes at lagoons. (b) Correlation between simulated tidal amplitudes and corresponding tide gauge data for the meshes identified in (a) that achieved $R^{2}>0.9$.

2021), assessment of each mesh's ability to faithfully represent the bathymetry is a crucial first step. To select the most appropriate mesh resolution, we use linear interpolation to evaluate the bathymetry on each unstructured mesh at all data points in the high-resolution bathymetry dataset as summarised in Table 2. As highlighted earlier, the resolution at the lagoons was varied; the mesh resolution at the coastline was maintained at $50 \mathrm{~m}$, and the mesh element size was allowed to increase up to a maximum of $15 \mathrm{~km}$ in open regions. The correlation (calculated via Eq. 5) between the interpolated bathymetry and the high-resolution bathymetry surface values for all data points is given in Fig. 4a, for varying resolutions at the lagoon. Discounting meshes which did not achieve a correlation of $90 \%$, the meshes which correspond to resolutions of 500, 300 and $100 \mathrm{~m}$ at the lagoon boundaries were then used to study the sensitivity of the resulting model outputs to mesh resolution (Fig. 4b).

The results of the sensitivity testing of model outputs, presented in Fig. 4b, show the correlation between the modelled and observed data at the tide gauge located in the harbour of Hulhulé Island. The data show that for meshes with element sizes at lagoons of 300 and $500 \mathrm{~m}$ the correlation coefficient between the tide gauge data and model results is below a threshold $R^{2}$ value of 0.9 . However, with a lagoon mesh resolution of $100 \mathrm{~m}$, a correlation coefficient of $R^{2} \approx 0.9$ is 
obtained. Based on this result the resolution of the triangular elements making up the multi-scale unstructured mesh was selected to be $100 \mathrm{~m}$ at the lagoon boundaries, since the resulting mesh is considered to be an adequate representation of the bathymetry and produces model results with adequate agreement with tide gauge observations.

\subsubsection{Distance to boundary}

Next, to study the model sensitivity to boundary distance, the model was run using the mesh parameters identified in Sect. 3.3.1 but with varying minimum distances to the boundary ranging from 2 to $20 \mathrm{~km}$ as shown in Fig. $5 \mathrm{c}$. The importance of the distance to the boundary has been highlighted in several studies including Jiang et al. (2020), who demonstrated the necessity to include adjacent regions when studying regional-scale tidal response to factors such as SLR. Similar issues have been discussed in the context of altering the tidal dynamics within a boundary forced tidal domain due to the installation of tidal energy devices within a model set-up (Adcock et al., 2011), the recommendation being to locate open boundaries beyond the continental shelf in relatively deep water to minimise inconsistencies between the altered dynamics within the domain which are not accounted for in the boundary data.

Initially we compare the correlation between model elevations and tide gauge data, seen in Fig. 5a, which shows that for all except the simulation with the $5 \mathrm{~km}$ minimum boundary distance the correlation coefficient $R^{2}>0.9$. The correlation at $2 \mathrm{~km}$ can be attributed to the close proximity to the forcing boundaries. Beyond $5 \mathrm{~km}$ there is no significant difference observed in the correlation of tidal amplitudes at the location of the tide gauge with increasing minimum distance to the boundary, with all values corresponding to 10,15 and $20 \mathrm{~km}$ choices showing similarly high correlation values. Since different locations are prone to variability in tidal elevations due to differences in topographic features and other factors (Pugh and Woodworth, 2014), next we compare the tidal elevations at different locations around the atoll, to understand the sensitivity of tidal elevations at different locations.

Figure $5 \mathrm{~b}$ shows the correlation of tidal amplitudes at three different locations in the domain. The locations, shown in Fig. 5c, were selected to coincide with channels on the east and west of the atoll which experience the maximum tidal currents, as well as a location in the centre of the atoll. Since there are no observational data available at these locations, we compare the elevations with the results of the simulation carried out using the maximum outer boundary distance of $20 \mathrm{~km}$. For all locations, a very good correlation coefficient is obtained with $R^{2}>0.98$, much higher than the threshold value of $R^{2}>0.9$. However, successive increases in the boundary distance show a successive increase in correlation with the 10 and the $15 \mathrm{~km}$ boundary results producing results
$R^{2}>0.99$ at all locations, providing confidence that $20 \mathrm{~km}$ is adequate as a boundary distance.

Based on the sensitivity study the mesh resolution at the lagoons (reef) boundaries were selected to be $100 \mathrm{~m}$, and the distance to the boundary was set at $20 \mathrm{~km}$. The simulations with the 2018 and SLR configurations were both carried out using 2018 coastlines with a mesh comprised of 190200 nodes and 380557 triangular elements, while the mesh used for the 1997 coastline had 184669 nodes and 369486 triangular elements.

\subsection{Grain size tidal model proxy}

Field data (Betzler et al., 2016), illustrated in Fig. 2 and described in Sect. 2.3.2, were further analysed using the GRADISTAT software (Blott and Pye, 2001) to calculate the $d_{50}$ values, following the procedure adopted by Ward et al. (2015). The $d_{50}$ value, which represents the particle diameter representing the $50 \%$ cumulative percentile value, is often used as a representative particle diameter for larger particle groups. Due to the limited number of field points (38 in total), all field points were used.

To develop the grain size tidal proxy, the modelled peak bed shear stress in floods was calculated using Eq. (4) and is shown in Fig. 7a. Due to the absence of a large inland mass to obstruct the flow, it is difficult to define the flood and ebb simply in terms of the reversal of tidal current patterns in coral atolls of the Maldives archipelago; rather we find the rise and fall of water elevations to be more appropriate. While previous studies have used different Manning coefficients for the numerical model and for calibrating bed shear stress for sediment (e.g. Martin-Short et al., 2015), here we find that the same Manning coefficient of $0.025 \mathrm{~s} \mathrm{~m}^{-1 / 3}$, which provides drag coefficients described in Sect. 3.2.3, gives results which are comparable to field observations. Next, shear stress values from the model, interpolated at the locations of field data points, were plotted against the calculated $d_{50}$ values from field data; this is shown in Fig. 6. Due to the limited number of field observations, a line was fit through the maximum of the bed shear stress values obtained for the simulation. The corresponding peak stress value for the maximum grain size for each sediment class was then obtained as summarised in Table 3, following the grain size classification scheme used in earlier field studies (Betzler et al., 2015). However, given the large values obtained at larger grain sizes in two different clusters, larger grain sizes in the range exceeding $2 \mathrm{~mm}$ were further split into two classes.

\subsection{Selection of SLR}

While it is clear that global mean sea level is rising (e.g. Church and White, 2006; IPCC, 2007; Church et al., 2013), the extent and rate of sea level rise is the subject of significant ongoing research. Analysis of long-term tide gauge data (Caldwell et al., 2015) at Hulhulé Island harbour indicates a 

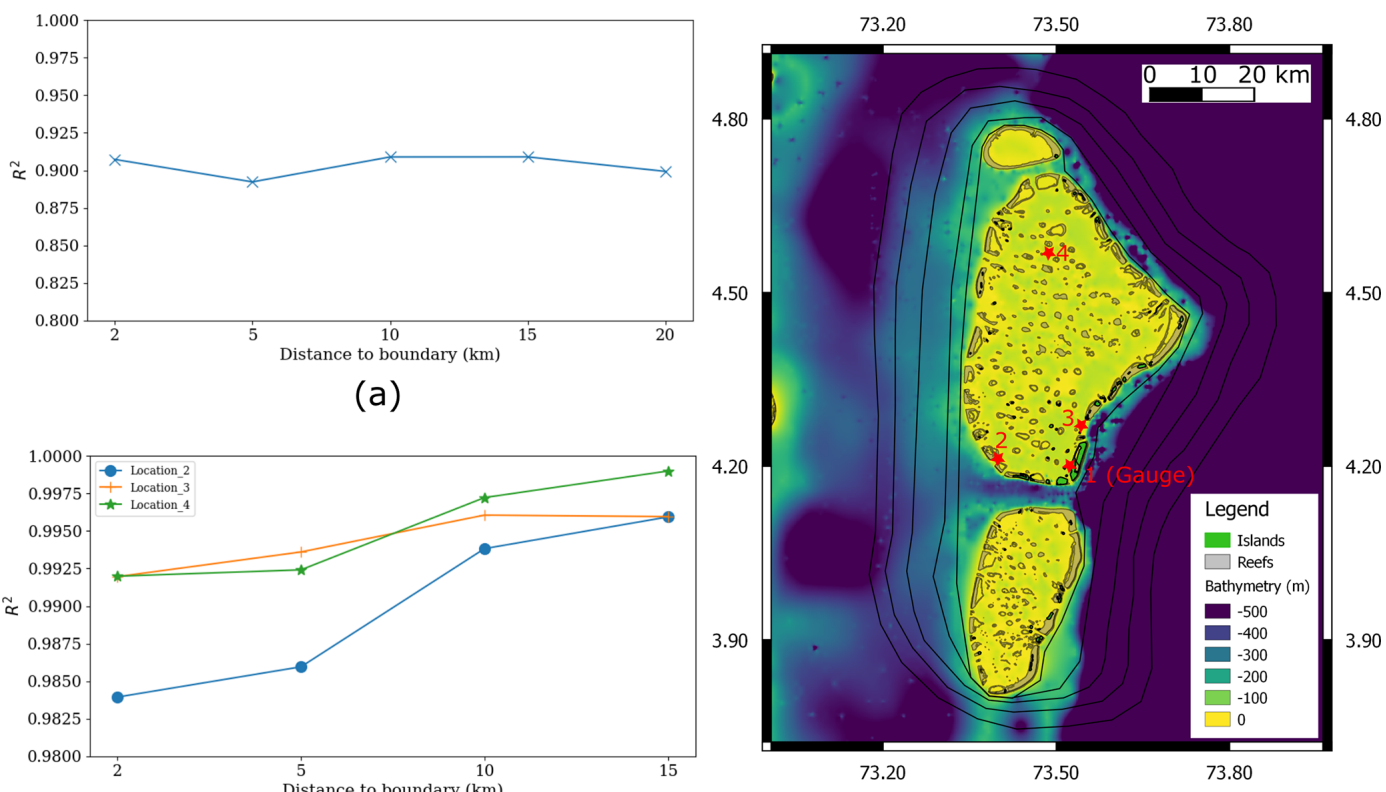

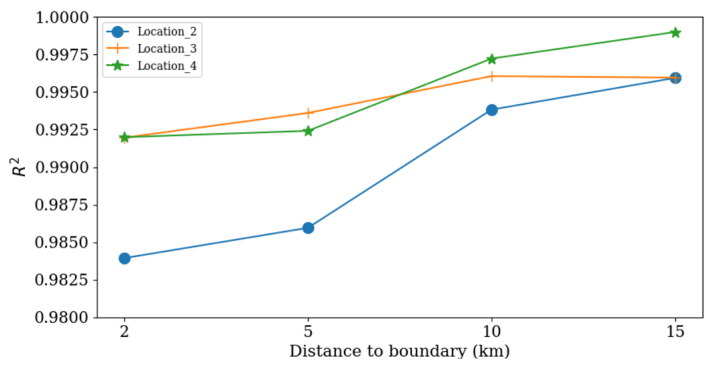

(b)

(c)

Figure 5. (a) Correlation between the simulation amplitudes and tide gauge data (at location 1 shown in c) for domains with different minimum distances to the open boundary. (b) Correlation between tidal amplitudes at different locations (labelled 2-4 in c) with varying distances to the boundary with tidal elevations obtained using the maximum boundary distance at $20 \mathrm{~km}$. (c) Visualisation of the different open-boundary locations used for the sensitivity study; the maximum westward boundary follows the $500 \mathrm{~m}$ depth contour at the Maldives inner sea where possible. Locations where the elevations are compared are marked in red.

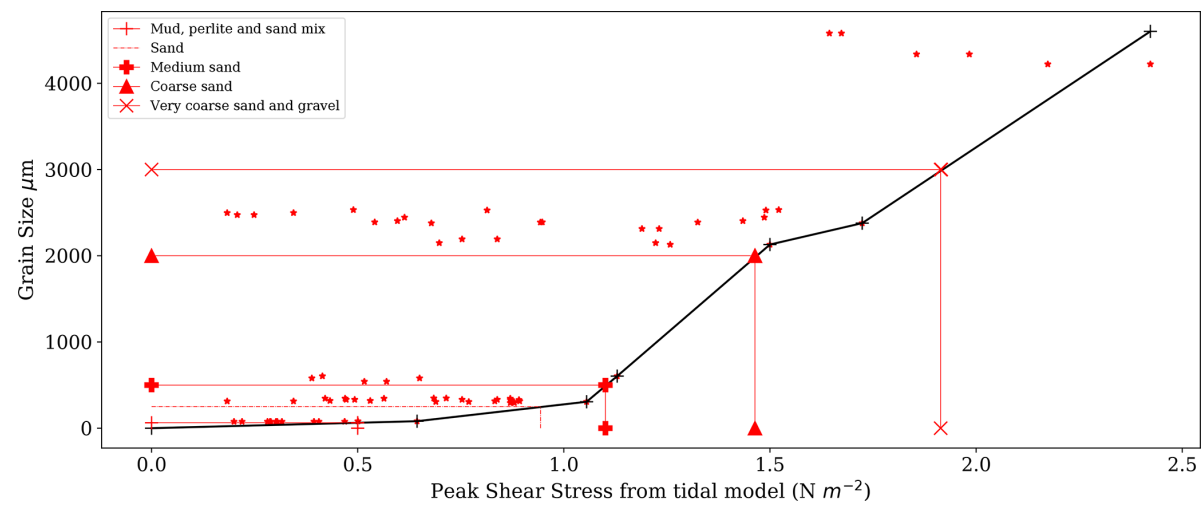

Figure 6. Median $d_{50}$ grain size values from Betzler et al. (2016) and associated peak shear stress values from the simulation. A line is fit through the maximum peak shear stress values derived from the simulation, with corresponding peak shear stress values for the grain size classes obtained (provided in Table 3).

current local mean sea level rise of $\sim 4.46 \mathrm{~mm} \mathrm{yr}^{-1}$, with an accelerating trend, which is in line with recent studies which quote a SLR rate of $3.93 \mathrm{~mm} \mathrm{yr}^{-1}$ over the period 1993 2018 for the Indian Ocean and the South Pacific obtained from observations of sea level (Frederikse et al., 2020). Some sources predict a global rise of 0.75 to $1.9 \mathrm{~m}$ by 2100 (Bindoff et al., 2007), while others predict much larger increases in sea level (Vermeer and Rahmstorf, 2009). The Fifth Assessment Report (AR5) of the Intergovernmental Panel on Climate Change (IPCC) proposes that a SLR of $1.0 \mathrm{~m}$ is un- likely before 2100 (Church et al., 2013). Additionally, studies of glaciological conditions leading to sea level rise indicate that a rise of more than $2 \mathrm{~m}$ is unlikely (Pfeffer et al., 2008). Reflecting this, studies incorporating sea level rise scenarios have used varying rates of increase when studying impacts using numerical models. Ward et al. (2012) used a $5 \mathrm{~m}$ rise in sea level to study the response of shelf seas to SLR, Pelling et al. (2013) used a SLR of $2 \mathrm{~m}$ to study the response of tides in the Bohai Sea, and Jiang et al. (2020) used successive rates of SLR up to $2 \mathrm{~m}$ to study the response of tides to SLR in a 
Table 3. Summary of sediment classes, corresponding grain sizes and modelled bed shear stress values for the developed grain size tidal proxy. The sediment classification is as used by Betzler et al. (2015),the largest grain size class was further split into two (Very Coarse Sand and Gravel and Pebbles and Grave).

\begin{tabular}{lrr}
\hline Sediment class & $\begin{array}{r}\text { Grain size } \\
\text { range } \\
(\mu \mathrm{m})\end{array}$ & $\begin{array}{r}\text { Modelled shear } \\
\text { stress range } \\
\left(\mathrm{N} \mathrm{m}^{2}\right)\end{array}$ \\
\hline Mud, pelite and sand mix & $<63$ & $<0.5$ \\
Sand & $63-250$ & $0.5-0.943606$ \\
Medium sand & $250-500$ & $0.943606-1.10092$ \\
Coarse sand & $500-2000$ & $1.10092-1.46362$ \\
Very coarse sand and gravel & $2000-3000$ & $1.46362-1.91552$ \\
Pebbles and gravel & $>3000$ & $>1.91552$ \\
\hline
\end{tabular}

tidal bay. In line with these studies as well as Bamber et al. (2019), which suggests the use of a global total SLR of $2 \mathrm{~m}$ for planning purposes in the 21 st century, in this work we also consider a SLR of $2 \mathrm{~m}$. This is an important figure as the islands of the Maldives generally have maximum heights of just over $2 \mathrm{~m}$ above sea level. Here we make the simplifying assumption that coastlines remain unchanged during the SLR process. This assumption holds true for many of the current coastlines of North Malé atoll, which are completely or partially protected by artificial barriers. While at other locations this assumption is admittedly hard to justify, we feel this is a reasonable and reproducible choice that avoids the addition of further uncertainties over how the coastlines will respond naturally and anthropologically to SLR.

\section{Results}

In this section we apply the grain size tidal proxy developed in Sect. 3.4 to estimate the current dominant grain size classes across North Malé, South Malé and Gaafaru atolls. Further, the changes to the dominant grain sizes across the atoll under different scenarios are derived and discussed.

\subsection{Grain size classification and validation}

The bed shear stress values obtained in the tidal model, and their classification into the dominant sediment classes using the bed shear tidal proxy developed above, are shown in Fig. 7.

Qualitatively, the model results compare well with the previous studies described in Sect. 2.3. Model results show that the atoll basin is primarily composed of sand. In contrast, regions experiencing high-flow velocities, particularly the outer flanks of the atoll rim, the inter atoll channels, openings along the atoll rim (channels), and the flanks of the steep oceanic lagoons inside the atoll, are comprised of coarser sediment; this is consistent with observations by Kohn (1964), Betzler et al. (2015) and others.

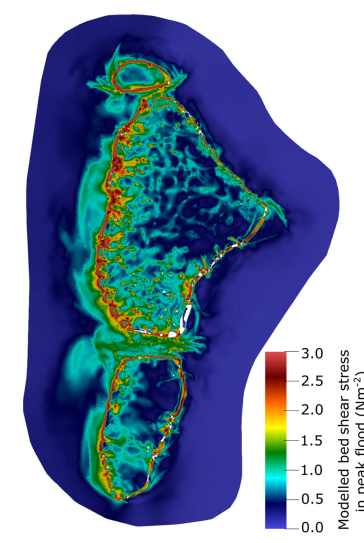

(a)

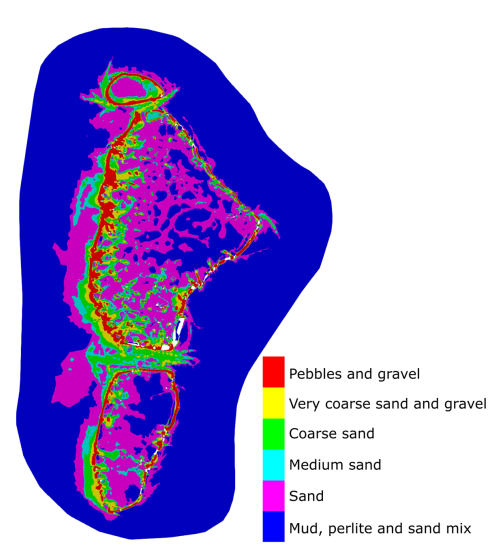

(b)
Figure 7. (a) Model bed shear stress values at peak flood. (b) Model bed shear stress values binned according to the grain size tidal proxy. The islands are shown in white with their details presented in Fig. 1. As the model does not include the impact of wind-driven sediment processes, differences in grain size in shallow areas (shown in grey in Fig. 1b) might arise.

At this resolution, the model also distinguishes sediment particle sizes within individual lagoons, with shallow exposed areas of the lagoons consisting of coarse particles, while the deeper, less exposed areas of individual lagoons are predicted to be comprised of fine particles, in line with observations of Felidhé atoll (Gischler et al., 2014). Additionally, the presence of sand on the eastern side of Gaafaru atoll (Gischler et al., 2014) is captured by the model as a region of medium and fine sand pits surrounded by particles of coarser grain size. The absence of such sand pits on the western side of the island, where the bed sediment is predicted by the model to be dominated by particles of a larger size, correlates well with satellite data. However, as the sediment processes at these relatively shallow depths are influenced by a variety of other factors (Gischler et al., 2014), further work is required to determine the origin of the discrepancy.

In addition, a qualitative comparison with bed sediment data gathered from environmental impact assessment surveys (CDE Consulting, 2020a, b), which provide a limited bed sediment assessment of the region, indicates that the predicted grain sizes compare well with field data. Comparison of bed sediment type with field data at 56 locations around North Malé atoll shows that the model predictions match observations across all locations except for fine sand pits located around the vicinity of islands. This can be attributed to the fact that the model does not incorporate wave-driven sediment patterns which dominate sediment transport in these shallow areas (Kench et al., 2009).

Next, we classified the bottom bed sediment for the simulations carried out using the 1997 coastline scenario, as well as under SLR of $2 \mathrm{~m}$. The same procedure described earlier was adopted and the changes in grain size were compared for 
each of the scenarios. Due to the vast majority of the coastal modifications occurring in North Malé atoll (Duvat and Magnan, 2019) we focus on results for this region.

\subsection{Predicted bed sediment classification change due to coastline modification}

Satellite imagery indicates that the landmass of North Malé atoll has more than doubled from $10.85 \mathrm{~km}^{2}$ composed of 75 individual islands in 1997 , to $26.51 \mathrm{~km}^{2}$ and 88 islands in 2018. Model results, shown in Fig. 8, predict that significant changes in grain sizes across the domain will have occurred as a result of coastline modification over the two decades. In general, the absolute difference in grain size class increase significantly in the immediate vicinity of areas where significant reclamation has taken place, including the lagoons of reclaimed islands. Significant differences in grain size class can also be seen around channels adjacent to major coastline modifications, arising from increased flow rates. Further, at this scale the model predicts large changes in bed sediment type at the island scale. For example, increased erosion patterns around the island of Kudabandos, observed since the large-scale reclamation of Hulhumalé island (CDE Consulting, 2020a), is predicted well in the simulation (Fig. 8a1). The model simulation shows that increased flow rate in the channel between the artificial island of Hulhumalé and the island of Kanifinolhu is the major contributor to the increased erosion, arising from further reclamation of Hulhumalé Island in 2016 completely blocking the flow across the lagoon and forcing the flow through the channel only. This provides confidence in the model results which predicts similar patterns of change in bed sediment arising from coastline modification. The results also highlight that the location of the reclamation area is important in influencing the erosion and accretion patterns, and the impact of reclamation locations needs to be further studied in major reclamation projects to minimise future damage.

In addition to sediment change driven by artificial reclamation, the results also indicate that tidal sediment in the atoll can be driven by natural changes in the lagoons which are influenced by seasonal wind patterns. Figure 8 shows that the formation of sand banks (Fig. 8b) in the Maabadhi lagoon of the Dhiffushi channel, which are present in the 2018 satellite images but absent in the satellite image captured in 1997, causes changes in bed sediment in the vicinity of the lagoon. These results predict that natural changes arising from the monsoon wind patterns in the region can influence tidal sediment of the atoll basin in the vicinity of the locations.

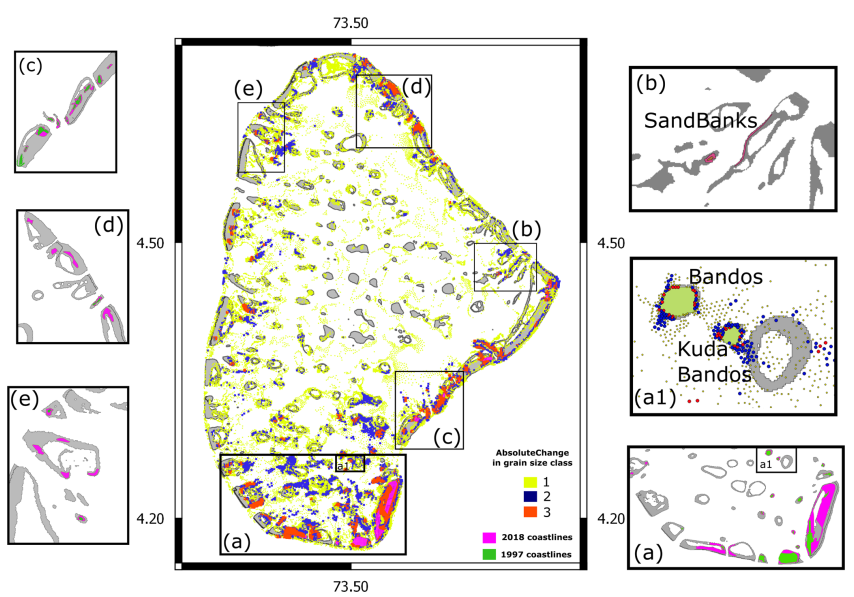

Figure 8. Absolute difference in bed sediment grain class predicted to have occurred between 1997-2018 due to changes in coastline. Spots coloured "yellow", "blue" and "red" are used to mark locations where an absolute grain size change of 1,2 or 3 classes has occurred. Panels (a)-(f) show some of the examples of changes to coastlines which have occurred from 1997 to 2018. Panel (a1) is a close-up of a region shown in (a) showing increased erosion in Kudabandos. Panel (b) shows the natural formation of sand banks in lagoons which is also predicted to contribute to grain size changes in the atoll basin. The boundaries of reef lagoons (Spalding et al., 2001) are shown in grey for better visualisation. Generally large changes are predicted in the areas where coastline changes have occurred, but change in grain size is also observed across the wider atoll basin.

\subsection{Predicted bed sediment classification change due to SLR of $2 \mathrm{~m}$}

Similar to the difference in grain size associated with coastline modification, a significant change in bed shear stress is observed with a SLR of $2 \mathrm{~m}$, as seen in Fig. 9. No change is predicted by the model at the channel entrances because the bed sediment at the entrances is already at the coarsest level, but the dominant bed sediment class in the proximity of the major channels does change, as fine particles are swept away leaving more coarse sediment. The model also predicts widespread changes to sediment class at the rims of the lagoons and faros of the inner atoll basin. It is also interesting to note that areas of significant reclamation such as the southern regions of North Malé atoll are predicted by the model to show an increased response with SLR. However, this requires further study to be verified and could arise from the change in flow across the region which has a higher concentration of faros.

\subsection{Discussion of results, limitations of the study and recommendations for improvement}

A comparison of the spatial extent of the predicted change in grain size from the two scenarios, shown in Fig. 10, indicates that artificial coastline change over a period of decades pro- 


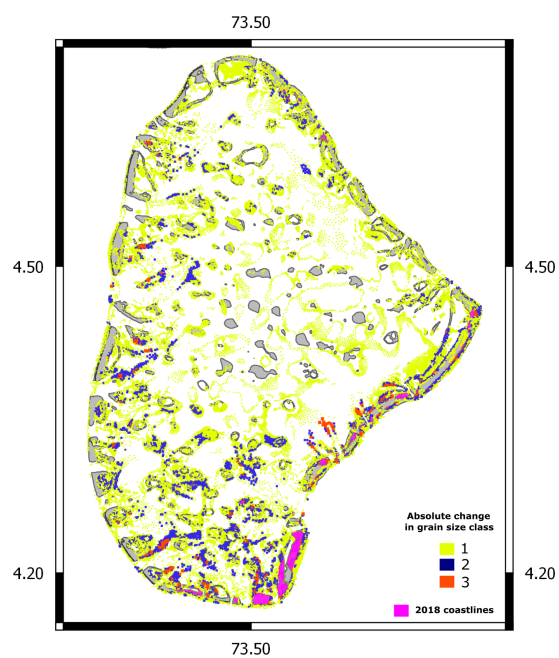

Figure 9. Absolute difference in bed sediment grain class arising from a sea level rise of $2 \mathrm{~m}$, with boundaries of lagoons from Spalding et al. (2001) in grey. Major changes in grain size class is predicted to occur near the channels and the lagoonal faros.

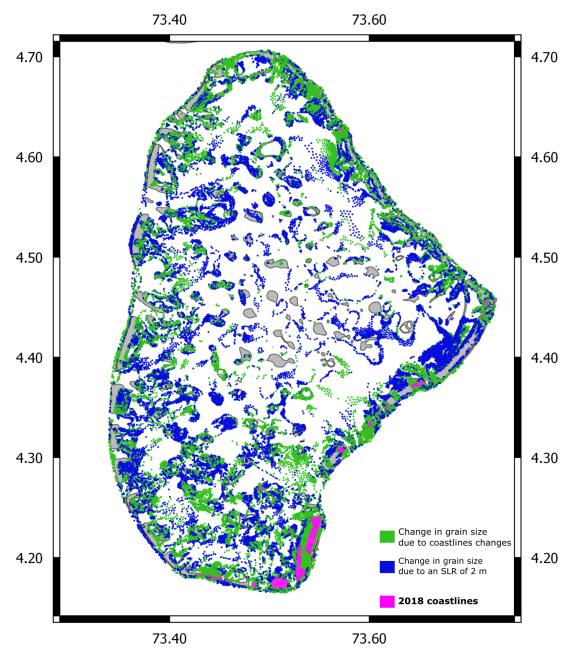

Figure 10. Comparison of changes to grain size class with different simulation scenarios, overlaid on boundaries of lagoons from Spalding et al. (2001) shown in grey. Even though there is generally more grain size class change across the atoll associated with SLR of $2 \mathrm{~m}$, considerable change is predicted with coastline modifications occurring over a far shorter timescale.

duces changes in bed sediment type which are comparable in magnitude to those due to long-term sea level rise. However, while changes associated with coastline change are more restricted to the vicinity of the modification itself, the predicted changes associated with SLR are more widespread.

These results agree with studies of other coral atolls around the world (e.g. Webb and Kench, 2010; Duvat and Pillet, 2017; Aslam and Kench, 2017; Duvat and Magnan, 2019), which highlights that the main changes driving morphological changes to islands are purely anthropogenic. Fur- ther, through the use of a high-resolution hydrodynamic model the results of this study predict that the effects of anthropogenic modifications to island coastlines are not only felt in the vicinity of the lagoons and island coastlines but are felt across the atoll with potentially far-reaching consequences. This provides further support to existing studies (Duvat and Magnan, 2019) which show that coastal modification can severely weaken the ability of islands in coral archipelagos to naturally adjust to pressures, increasing their vulnerability to future changes in ocean and climate.

The main limitation of this study is the sparsity of available field data. While field data describing grain size for the domain were accessible, the data are relatively scarce. Availability of more field data would enhance the results. Furthermore, tide gauge data were only available for one location within the considered domain and this was located within a sheltered harbour. Additional tide gauge data would help to further validate the model results and increase confidence in the model set-up and corresponding simulation results.

Additionally, the model results as well as the bed shear stress are highly sensitive to the bathymetry. While this study was made possible by the newly available high-resolution bathymetry dataset (Rasheed et al., 2021), which contains data from a variety of sources collected over decades, it is likely that the bathymetry data will contain some errors which impact the final grain size approximation. Further, the inclusion of the changes to coastlines with SLR also needs to be included in the model to fully understand the impacts of SLR. This need is further demonstrated in this study, in that coastline modification at the island scale is shown to have a large impact across the atoll. To facilitate accurate studies, additional detailed bathymetry and coastline data for the region would be beneficial.

Finally, this study focuses on tidally driven large-scale bottom sediment classification within the larger atoll, with model performance comparable to observational data. To account for the shallow lagoon areas, wind-driven sediment can be incorporated into the model in future works; however, this requires field data currently not available for model set-up and calibration.

\section{Conclusions}

A classified bed sediment map of North Malé atoll, South Malé atoll and Gaafaru atoll has been developed from tidal model simulations. To provide confidence in model results, a sensitivity study was undertaken and the model results were compared to observational data. The grain sizes predicted by the model compare well with qualitative and quantitative data reported at the coral atolls of the Maldives archipelago, demonstrating that correctly configured tidal models can be effectively used to determine dominant grain size in coral atolls at the atoll scale. Identification of dominant bed sediment types in coral atolls can have a wide range of uses 
ranging from industrial seabed mining to the identification of potential marine flora and fauna habitats.

The response of the estimated bed sediment with coastline changes shows that a significant change in bed grain size distribution occurs at a localised island scale in line with established studies. Using a high-resolution bathymetry dataset coupled with high-resolution hydrodynamic modelling, we have shown here that this change is not limited to the direct vicinity of the island but can be seen across the wider atoll basin, consistent with reported observations across the atolls of the Maldives archipelago where significant erosion patterns have been observed in the past few decades without any other major change being reported other than significant island-scale modification. While tipping-point thresholds for island destabilisation are not sufficiently well understood (Duvat and Pillet, 2017) to allow predictions for whether these changes are overall detrimental or beneficial in the long term, statistics (DNP, 2019) show that more than 114 of the 198 locally inhabited islands of the Maldives archipelago (excluding uninhabited and industrial islands) reported severe erosion during the period 2012-2018, endangering long-established island communities and existing socio-economic activities.

Importantly, model predictions show that the change in bed shear grain size associated with a sea level rise of $2 \mathrm{~m}$, which is predicted to occur over timescales ranging from decades to centuries, is comparable to the change in dominant grain size associated with island-scale coastline modification which has occurred in the relatively short period of two decades. The results of this study, derived from detailed numerical modelling, provide support for recent studies which found evidence that artificial coastline modification can be a major factor in increasing the vulnerability of islands (Duvat and Magnan, 2019). With major reclamation work being continuously undertaken in the Maldives archipelago at an industrial scale, and with rates accelerating over the past few years to accommodate major socioeconomic activities, the results of this study point to the urgent need for further work to understand the large-scale impacts of coastal modifications.

Further, the results of this study have shown that with recent developments in the availability of high-resolution bathymetry datasets, it is now possible to use hydrodynamic modelling in the Maldives archipelago to study the impact of existing and future coastal modification scenarios at a range of spatial and temporal scales, ranging from open atoll basins to the island scale; these are activities which are generally not currently undertaken in the country (CDE Consulting, 2020a). The methods developed in this study can be easily adapted for application to other similar geographic locations, where in general field data are sparse, and data collection may be hindered for a variety of reasons.
Code availability. The source code of THETIS coastal ocean model used in this study is available from https://thetisproject. org/ (last access: 15 January 2019) as well as https://github.com/ thetisproject/thetis (Kärnä et al., 2018).

Data availability. The satellite imagery used for coastline extraction is available from Landsat-5 (courtesy of the US Geological Survey/NOAA) and Sentinel 2 (image courtesy of the European Space Agency). Tide gauge data for the three tide gauges across the Maldives are available from the University of Hawaii Sea Level Center (https://doi.org/10.7289/V5V40S7W, Caldwell et al., 2015). Please refer to Rasheed et al. (2021) for the bathymetry used in this study.

Author contributions. SR ran the simulations, carried out the analysis of results and initiated the writing of the paper. SCW provided support for model set-up and analysis of the results. MDP and YP provided supervision, guidance and insights at every stage of the project. All authors participated in the writing and editing of the paper.

Competing interests. The authors declare that they have no conflict of interest.

Acknowledgements. The authors would like to acknowledge funding from a Research England GCRF award made to Imperial College London. Shuaib Rasheed would like to acknowledge PhD funding from the Islamic Development Bank and Imperial College London.

Review statement. This paper was edited by Joanne Williams and reviewed by two anonymous referees.

\section{References}

Adcock, T. A. A., Borthwick, A. G. L., and Houlsby, G. T.: The open boundary problem in tidal basin modelling with energy extraction, 9th European Wave and Tidal Energy Conference (EWTEC), September 2011, Southampton, UK, 2011.

Agassiz, A.: ART. XXIV. - An Expedition to the Maldives, (18801910), Am. J. Sci., 13, 297, 1902.

Angeloudis, A., Kramer, S. C., Avdis, A., and Piggott, M. D.: Optimising tidal range power plant operation, Appl. Energ., 212, 680-690, 2018.

Areas, G. A.: GADM Database of Global Administrative Areas, version 2.8. 2015, available at: http://www.gadm.org (last access: 15 December 2019), 2018.

Aslam, M. and Kench, P. S.: Reef island dynamics and mechanisms of change in Huvadhoo Atoll, Republic of Maldives, Indian Ocean, Anthropocene, 18, 57-68, 2017.

Aubert, O. and Droxler, A.: General Cenozoic evolution of the Maldives carbonate system (equatorial Indian Ocean), Bull. Cent. Rech. Elf. E., 16, 113-136, 1992. 
Aubert, O. and Droxler, A.: Seismic stratigraphy and depositional signatures of the Maldive carbonate system (Indian Ocean), Mar. Petrol. Geol., 13, 503-536, 1996.

Avdis, A., Jacobs, T. C., Mouradian, L. S., Hill, J., and Piggott, D. M.: Meshing ocean domains for coastal engineering applications, in: The European Community on Computational Methods in Applied Sciences and Engineering (ECCOMAS) VII Congress Proceedings, 5-10 June 2016, Crete, Greece, 2016.

Avdis, A., Candy, A. S., Hill, J., Kramer, S. C., and Piggott, M. D.: Efficient unstructured mesh generation for marine renewable energy applications, Renew. Energ., 116, 842-856, https://doi.org/10.1016/j.renene.2017.09.058, 2018.

Bamber, J. L., Oppenheimer, M., Kopp, R. E., Aspinall, W. P., and Cooke, R. M.: Ice sheet contributions to future sea-level rise from structured expert judgment, P. Natl. Acad. Sci. USA, 116, 11195-11200, 2019.

Belopolsky, A. V. and Droxler, A. W.: Imaging Tertiary carbonate system - the Maldives, Indian Ocean: insights into carbonate sequence interpretation, The Leading Edge, 22, 646-652, 2003.

Belopolsky, A. V. and Droxler, A. W.: Seismic expressions and interpretation of carbonate sequences: the Maldives platform, equatorial Indian Ocean, 49, https://doi.org/10.1306/St49974, 2004.

Betzler, C., Lindhorst, S., Lüdmann, T., Weiss, B., Wunsch, M., and Braga, J. C.: The leaking bucket of a Maldives atoll: implications for the understanding of carbonate platform drowning, Mar. Geol., 366, 16-33, https://doi.org/10.1016/j.margeo.2015.04.009, 2015.

Betzler, C., Lindhorst, S., Lüdmann, T., Weiß, B., Wunsch, M., and Braga, J. C.: Grain size distribution of the lagoonal deposits within the South Malé Atoll, Maldives, Indian Ocean, PANGAEA, https://doi.org/10.1594/PANGAEA.858886, 2016.

Bindoff, N. L., Willebrand, J., Artale, V., Cazenave, A., Gregory, J. M., Gulev, S., Hanawa, K., Le Quere, C., Levitus, S., Nojiri, Y., Shum, C. K., Talley, L. D., and Unnikrishnan, A. S.: Climate change 2007: The physical science basis. Contribution of Working Group first to the fourth assessment report of the intergovernmental panel on climate change, edited by: Solomon, S., Qin, D., Manning, M., Marquis, M., Averyt, K., Tignor, M. M. B., Miller, H. L., and Chen, Z., 385-432, Cambridge University Press, 2007.

Blott, S. J. and Pye, K.: GRADISTAT: a grain size distribution and statistics package for the analysis of unconsolidated sediments, Earth Surf. Proc. Land., 26, 1237-1248, 2001.

Caldwell, P., Merrifield, M., and Thompson, P.: Sea level measured by tide gauges from global oceans - the Joint Archive for Sea Level holdings (NCEI Accession 0019568), Version 5.5, NOAA National Centers for Environmental Information, Dataset, 10, V5V40S7W, https://doi.org/10.7289/V5V40S7W, 2015.

CDE Consulting: EIA for the proposed dredging, land reclamation, and revetment work at Gulhifalhu, Tech. Rep., Ministry of Planning and National Development, available at: http://files.epa.gov. mv/file/1522 (last access: 25 January 2019), 2020a.

CDE Consulting: EIA For The Proposed Port Development Project At Gulhifalhu, North Malé Atoll Phase I Dredging, Land Reclamation And Revetment Works, Tech. Rep., Ministry of Planning and National Development, available at: http://files.epa.gov.mv/ file/1581 (last access: 14 October 2020), 2020b.
Church, J. A. and White, N. J.: A 20th century acceleration in global sea-level rise, Geophys. Res. Lett., 33, L01602, https://doi.org/10.1029/2005GL024826, 2006.

Church, J. A., Clark, P. U., Cazenave, A., Gregory, J. M., Jevrejeva, S., Levermann, A., Merrifield, M. A., Milne, G. A., Nerem, R. S., and Nunn, P. D.: Climate Change 2013: The Physical Science Basis. Contribution of Working Group I to the Fifth Assessment Report of the Intergovernmental Panel on Climate Change, edited by: Stocker, T. F., Qin, D., Plattner, G.-K., Tignor, M., Allen, S. K., Boschung, J., Nauels, A., Xia, Y., Bex, V., and Midgley, P. M., Cambridge, UK, 1137-1216, 2013.

Ciarapica, G. and Passeri, L.: An overview of the Maldivian coral reefs in Felidu and North Male atoll (Indian Ocean): platform drowning by ecological crises, Facies, 28, 33, https://doi.org/10.1007/BF02539727, 1993.

Darwin, C. R.: The structure and distribution of coral reefs, Being the first part of the geology of the voyage of the Beagle, under the command of Capt. Fitzroy, R. N. during the years 1832 to 1836, Smith Elder and Co., London, 1842.

DNP: Statistical Year Book of Maldives 2019, available at: http: //statisticsmaldives.gov.mv/yearbook/2019/ (last access: 20 May 2020), 2019.

Duvat, V. K. and Pillet, V.: Shoreline changes in reef islands of the Central Pacific: Takapoto Atoll, Northern Tuamotu, French Polynesia, Geomorphology, 282, 96-118, 2017.

Duvat, V. K. and Magnan, A. K.: Rapid human-driven undermining of atoll island capacity to adjust to ocean climate-related pressures, Sci. Rep.-UK, 9, 1-16, 2019.

East, H. K., Perry, C. T., Beetham, E. P., Kench, P. S., and Liang, Y.: Modelling reef hydrodynamics and sediment mobility under sea level rise in atoll reef island systems, Global Planet. Change, 192, 103196, https://doi.org/10.1016/j.gloplacha.2020.103196, 2020.

Egbert, G. D. and Erofeeva, S. Y.: Efficient inverse modeling of barotropic ocean tides, J. Atmos. Ocean. Tech., 19, 183-204, 2002.

Frederikse, T., Landerer, F., Caron, L., Adhikari, S., Parkes, D., Humphrey, V. W., Dangendorf, S., Hogarth, P., Zanna, L., and Cheng, L.: The causes of sea-level rise since 1900, Nature, 584, 393-397, 2020.

Gardiner, J. S.: The Formation of the Maldives, Geogr. J., 19, 277296, https://doi.org/10.2307/1775312, 1902.

Gardiner, J. S.: The Fauna and Geography of the Maldive and Laccadive Archipelagoes: Being the Account of the Work Carried on and of the Collections Made by an Expedition During the Years 1899 and 1900, 1, Cambridge University Press, Cambridge, 1903.

Geuzaine, C. and Remacle, J. F.: Gmsh: A 3D finite element mesh generator with built-in pre- and post-processing facilities, Int. J. Numer. Meth. Eng., 79, 1309-1331, https://doi.org/10.1002/nme.2579, 2009.

Gischler, E.: Sedimentation on Rasdhoo and Ari Atolls, Maldives, Indian Ocean, Facies, 52, 341-360, 2006.

Gischler, E., Storz, D., and Schmitt, D.: Sizes, shapes, and patterns of coral reefs in the Maldives, Indian Ocean: the influence of wind, storms, and precipitation on a major tropical carbonate platform, Carbonate. Evaporite., 29, 73-87, 2014.

Glennie, E. A.: A report on the values of gravity in the Maldive and Laccadive Islands, Order of the Trustees of the British Museum, Sci. Rep. John Murray Exped. 1933-34, 1, 95-108 1936. 
Haigh, I. D., Pickering, M. D., Green, J. M., Arbic, B. K., Arns, A., Dangendorf, S., Hill, D. F., Horsburgh, K., Howard, T., and Idier, D.: The Tides They Are A-Changin': A Comprehensive Review of Past and Future Nonastronomical Changes in Tides, Their Driving Mechanisms, and Future Implications, Rev. Geophys., 58, e2018RG000636, https://doi.org/10.1029/2018RG000636, 2020.

Hass, H.: Expedition into the unknown: a report on the expedition of the research ship Xarifa to the Maldive and the Nicobar Islands and on a series of 26 television films, Hutchinson, 167 pp., 1965.

Holleman, R. C. and Stacey, M. T.: Coupling of sea level rise, tidal amplification, and inundation, J. Phys. Oceanogr., 44, 14391455, 2014.

IPCC: The physical science basis, Contribution of working group I to the fourth assessment report of the Intergovernmental Panel on Climate Change, Cambridge University Press, Cambridge, UK and New York, USA, 996, 2007.

Jiang, L., Gerkema, T., Idier, D., Slangen, A. B. A., and Soetaert, K.: Effects of sea-level rise on tides and sediment dynamics in a Dutch tidal bay, Ocean Sci., 16, 307-321, https://doi.org/10.5194/os-16-307-2020, 2020.

Kärnä, T., De Brye, B., Gourgue, O., Lambrechts, J., Comblen, R., Legat, V., and Deleersnijder, E.: A fully implicit wetting-drying method for DG-FEM shallow water models, with an application to the Scheldt Estuary, Comput. Method. Appl. M., 200, 509524, 2011

Kärnä, T., Kramer, S. C., Mitchell, L., Ham, D. A., Piggott, M. D., and Baptista, A. M.: Thetis coastal ocean model: discontinuous Galerkin discretization for the threedimensional hydrostatic equations, Geosci. Model Dev., 11, 4359-4382, https://doi.org/10.5194/gmd-11-4359-2018, 2018 (code available at: https://github.com/thetisproject/thetis, last access: 15 January 2019).

Kench, P. S. and Brander, R. W.: Response of reef island shorelines to seasonal climate oscillations: South Maalhosmadulu atoll, Maldives, J. Geophys. Res.-Earth, 111, F01001, https://doi.org/10.1029/2005JF000323, 2006.

Kench, P. S., Parnell, K., and Brander, R.: Monsoonally influenced circulation around coral reef islands and seasonal dynamics of reef island shorelines, Mar. Geol., 266, 91-108, 2009.

Kenyon, N. H.: Sand ribbons of European tidal seas, Mar. Geol., 9, 25-39, 1970.

Klostermann, L. and Gischler, E.: Holocene sedimentary evolution of a mid-ocean atoll lagoon, Maldives, Indian Ocean, Int. J. Earth Sci., 104, 289-307, 2015.

Klostermann, L., Gischler, E., Storz, D., and Hudson, J. H.: Sedimentary record of late Holocene event beds in a mid-ocean atoll lagoon, Maldives, Indian Ocean: potential for deposition by tsunamis, Mar. Geol., 348, 37-43, 2014.

Kohn, A. J.: Notes on reef habitats and gastropod molluscs of a lagoon island at North Male Atoll, Maldives, Atoll Research Bulletin, 102, 1-5, https://doi.org/10.5479/si.00775630.102.1, 1964.

Kraines, S., Yanagi, T., Isobe, M., and Komiyama, H.: Wind-wave driven circulation on the coral reef at Bora Bay, Miyako Island, Coral Reefs, 17, 133-143, 1998.

Luthfee, M. I.: Dhivehi Raajjeige Geographyge' Vanavaru, Ministry of Education, Dhivehi, 1995.

Martin-Short, R., Hill, J., Kramer, S., Avdis, A., Allison, P., and Piggott, M.: Tidal resource extraction in the Pentland Firth, UK:
Potential impacts on flow regime and sediment transport in the Inner Sound of Stroma, Renew. Energ., 76, 596-607, 2015.

Morgan, K. and Kench, P.: A detrital sediment budget of a Maldivian reef platform, Geomorphology, 222, 122-131, 2014.

Naseer, A.: The integrated growth response of coral reefs to environmental forcing: morphometric analysis of coral reefs of the Maldives, PhD thesis, Dalhousie University, Halifax, Nova Scotia, 2003.

Naseer, A. and Hatcher, B. G.: Assessing the integrated growth response of coral reefs to monsoon forcing using morphometric analysis of reefs in Maldives, in: Proceedings 9th International Coral Reef Symposium, 23-27 October 2000, Bali, Indonesia, Vol. 1, 75-80, 2000.

Naseer, A. and Hatcher, B. G.: Inventory of the Maldives' coral reefs using morphometrics generated from Landsat ETM+ imagery, Coral Reefs, 23, 161-168, 2004.

O’Neill, C. K., Polton, J. A., Holt, J. T., and O’Dea, E. J.: Modelling temperature and salinity in Liverpool Bay and the Irish Sea: sensitivity to model type and surface forcing, Ocean Sci., 8, 903-913, https://doi.org/10.5194/os-8-903-2012, 2012.

Owen, A., Kruijsen, J., Turner, N., and Wright, K.: Marine Energy in the Maldives, prefeasibility report on Scottish Support for Maldives Marine Energy Implementation, Part II, Annex III: Currents, available at: https://minivannewsarchive.com/files/ 2011/09/Marine-Energy-in-the-Maldives-Report.pdf (last access: 1 April 2020), 2011.

Pan, W., Kramer, S. C., and Piggott, M. D.: Multi-layer non-hydrostatic free surface modelling using the discontinuous Galerkin method, Ocean Model., 134, 68-83, https://doi.org/10.1016/j.ocemod.2019.01.003, 2019.

Parker, J. H. and Gischler, E.: Modern foraminiferal distribution and diversity in two atolls from the Maldives, Indian Ocean, Mar. Micropaleontol., 78, 30-49, 2011.

Pelling, H., Uehara, K., and Green, J.: The impact of rapid coastline changes and sea level rise on the tides in the Bohai Sea, China, J. Geophys. Res.-Ocean, 118, 3462-3472, 2013.

Pfeffer, W. T., Harper, J. T., and O’Neel, S.: Kinematic constraints on glacier contributions to 21 st-century sea-level rise, Science, 321, 1340-1343, 2008.

Piggott, M. D., Pain, C. C., Gorman, G. J., Marshall, D. P., and Killworth, P. D.: Unstructured adaptive meshes for ocean modeling, in: Ocean Modeling in an Eddying Regime, edited by: Hecht, M. and Hasumi, H., 383-408, https://doi.org/10.1029/177GM22, 2008.

Pingree, R. and Griffiths, D.: Sand transport paths around the British Isles resulting from M 2 and M 4 tidal interactions, J. Mar. Biol. Assoc. UK, 59, 497-513, 1979.

Pugh, D. and Woodworth, P.: Sea-level science: understanding tides, surges, tsunamis and mean sea-level changes, Cambridge University Press, Cambridge, UK and New York, USA, 395 pp., 2014.

Purdy, E. G. and Bertram, G. T.: Carbonate concepts from the Maldives, Indian Ocean, American Association of Petroleum Geologists, https://doi.org/10.1306/St34568, 1993.

Rasheed, S., C Warder, S., Plancherel, Y., and Piggott, M. D.: An Improved Gridded Bathymetric Dataset and Tidal Model for the Maldives Archipelago, Earth and Space Science, in review, 2021

Rathgeber, F., Ham, D. A., Mitchell, L., Lange, M., Luporini, F., Mcrae, A. T. T., Bercea, G.-T., Markall, G. R., and Kelly, 
P. H. J.: Firedrake: Automating the Finite Element Method by Composing Abstractions, ACM T. Math. Software, 43, 24, https://doi.org/10.1145/2998441, 2016.

Rosman, J. H. and Hench, J. L.: A framework for understanding drag parameterizations for coral reefs, J. Geophys. Res.-Ocean, 116, C08025, https://doi.org/10.1029/2010JC006892, 2011.

Spalding, M., Spalding, M. D., Ravilious, C., and Green, E. P.: World atlas of coral reefs, University of California Press, Berkeley, USA, 424 pp., 2001.

Vermeer, M. and Rahmstorf, S.: Global sea level linked to global temperature, P. Natl. Acad. Sci. USA, 106, 21527-21532, 2009.

Ward, S. L., Green, J. M., and Pelling, H. E.: Tides, sea-level rise and tidal power extraction on the European shelf, Ocean Dynam., 62, 1153-1167, 2012.

Ward, S. L., Neill, S. P., Van Landeghem, K. J., and Scourse, J. D.: Classifying seabed sediment type using simulated tidal-induced bed shear stress, Mar. Geol., 367, 94-104, 2015.
Warder, S. C., Angeloudis, A., Kramer, S. C., Cotter, C. J., and Piggott, M. D.: A comparison of Bayesian inference and gradientbased approaches for friction parameter estimation, submitted to Ocean Model., https://doi.org/10.31223/osf.io/mv9qy, online first, 2020.

Warwick, R. and Uncles, R.: Distribution of benthic macrofauna associations in the Bristol Channel in relation to tidal stress, Mar Ecol.-Prog. Ser., 3, 97-103, 1980.

Webb, A. P. and Kench, P. S.: The dynamic response of reef islands to sea-level rise: Evidence from multi-decadal analysis of island change in the Central Pacific, Global Planet. Change, 72, 234 246, 2010.

Wells, S.: Coral Reefs of the World, Indian Ocean, Red Sea and Gulf, UNEP Regional Seas Directories and Bibliographies, IUCN, Gland, Switzerland and Cambridge, UK/UNEP, Nairobi, Kenya, 1988. 